\title{
Detecting DNA Polymorphism and Genetic Diversity in a Wide Pistachio Germplasm: Comparison of AFLP, ISSR, and RAPD Markers
}

\author{
Salih Kafkas ${ }^{1}$ \\ Department of Horticulture, Faculty of Agriculture, University of Cukurova, 01330, Adana, Turkey \\ Hakan Ozkan \\ Department of Field Crops, Faculty of Agriculture, University of Cukurova, 01330, Adana, Turkey \\ Bekir Erol Ak \\ Department of Horticulture, Faculty of Agriculture, University of Harran, Sanliurfa, Turkey \\ Izzet Acar and Halit Seyfettin Atli \\ Pistachio Research Institute, Gaziantep, Turkey
}

Sonay Koyuncu

Department of Horticulture, Faculty of Agriculture, University of Cukurova, 01330, Adana, Turkey

AdDITIONAL INDEX wORDs. Pistacia vera, similarity, characterization, clustering, resolving power, UPGMA

\begin{abstract}
There are limited numbers of pistachio (Pistacia vera $L$.) cultivars in the world and their phenotypic appearance and productivity are variable. Understanding such variation would facilitate their use in cultivar breeding programs. Therefore, in this study, 69 pistachio cultivars and genotypes originating from seven countries were characterized by randomly amplified polymorphic DNA (RAPD), inter-simple sequence repeats (ISSR), and amplified fragment-length polymorphism (AFLP) markers. The results showed that all three marker systems were able to reveal variability between pistachio cultivars and genotypes. The correlation coefficients for genetic distances were statistically significant among all three molecular marker types. The correlation between RAPD and AFLP data was the highest $(r=0.73)$ and the value between RAPD and ISSR data was the lowest $(r=0.58)$. AFLP proved to be the best technique among them. ISSR and AFLP assays were reliable and produced reproducible bands. ISSR was preferred over RAPD, especially when financial investment and technical knowledge are limited. The constructed unweighted pair group method with arithmetic averages (UPGMA) dendrogram obtained from combined data separated the genotypes into two main clusters: one cluster ("Iranian") included genotypes originating from Iran and the second cluster ("Mediterranean") contained most other genotypes. The "Mediterranean" cluster further divided into three subclusters: one ("Siirt") consisted of the cultivars Siirt and Hacireso with a few other selections; the second subcluster ("Turkish") included Turkish cultivars; and the third subcluster contained Syrian, Italian, and the remaining cultivars. The closeness of the clusters was "Iranian" - "Siirt" - "Turkish"/“Syrian." These findings reveal a new understanding in the diffusion of pistachio cultivation from its center of origin, the Iranian-Caspian region, via southeastern Turkey to Syria, the Mediterranean region of Europe, and northern Africa.
\end{abstract}

The genus Pistacia L. is a member of the Anacardiaceae family and consists of at least 11 species (Zohary, 1952). Among these species, $P$.vera (pistachio) is the only cultivated and economically important species. Pistacia vera is native to north Afghanistan, northeast Iran, and central Asian republics (Browicz, 1988; Kafkas, 2006). Pistacia species are dioecious with several exceptions (Crane, 1974; Kafkas et al., 2000; Ozbek and Ayfer, 1958). Pistachio is a diploid $(2 \mathrm{n}=30, \mathrm{X}=15)$ and wind-pollinated tree (Ila et al., 2003).

Pistacia vera is believed to be the most ancestral species and the other species are probably its derivatives (Zohary, 1952). There are two centers of diversity of $P$. vera: one extends from

Received for publication 17 Dec. 2005. Accepted for publication 29 Apr. 2006 The authors express their gratitude to the Turkish Republic Prime Ministry State Planning Organization (Project No. 2002K120180-D) and University of Cukurova, Scientific Research Projects Unit (Projects No. KAP2002ZF-38 and ZF2003KAP-15), for financial support. We are also thankful to Dr. Patrick F. Byrne for critical review of the manuscript.

${ }^{1}$ To whom reprint requests should be addressed. E-mail address: skafkas@mail. cu.edu.tr; phone: +90 (322) 33860 30; fax: +90 (322) 3386388.
Crimea to the Caspian Sea and the second comprises the Mediterranean region of Europe, northern Africa, and the Middle East (Hormaza et al., 1994a; Maggs, 1973). The major pistachio-producing countries of the world are, in order, Iran, U.S., Turkey, Syria, and to a lesser extent, China, Greece, and Italy (Food and Agriculture Organization of the United Nations, 2005). The major cultivars in the world are 'Ohadi' and 'Kalehghouchi' in Iran (Shebani, 1995); 'Kerman' and 'Peters' in the U.S. (Ferguson, 1995); and 'Kirmizi', 'Uzun', 'Halebi', 'Siirt', and 'Ohadi' in Turkey (Kaska, 1995).

Polymerase chain reaction (PCR) technology has promoted the development of a range of molecular assay systems that detect polymorphism at the DNAlevel.Among them, RAPD (Williams et al., 1990) has been the most commonly used method in pistachio to characterize cultivars (Hormaza et al., 1994a, 1998; Katsiotis et al., 2003), assess genetic variability in Turkmen wild $P$. vera populations (Barazani et al., 2003), and find sex markers in $P$. vera (Hormaza et al., 1994b). AFLP technique was used previously in pistachio to characterize eight male and female cultivars (Katsiotis et al., 2003). 
Table 1. List of pistachio cultivars and their origins examined for genetic relatedness using AFLP, ISSR, and RAPD marker systems in this study.

\begin{tabular}{|c|c|c|c|c|c|c|c|c|c|}
\hline No. & $\begin{array}{l}\text { Cultivars/ } \\
\text { genotypes }\end{array}$ & $\mathrm{Sex}^{\mathrm{z}}$ & Germplasm ${ }^{y}$ & Origin & No. & $\begin{array}{l}\text { Cultivars/ } \\
\text { genotypes }\end{array}$ & Sex & Germplasm & Origin \\
\hline 1 & Aeginea & $\mathrm{F}$ & USDA/Adana & Greece & 36 & Manisa-2 & $\mathrm{M}$ & Adana & Turkey \\
\hline 2 & Ajamy-1 & $\mathrm{F}$ & Spain/Adana & Syria & 37 & Mumtaz-1 & $\mathrm{F}$ & Iran/Gaziantep & Iran \\
\hline 3 & Ajamy-2 & $\mathrm{F}$ & Syria/Gaziantep & Syria & 38 & Mumtaz-2 & $\mathrm{F}$ & Iran/Sanliurfa & Iran \\
\hline 4 & Ashoury & F & Syria/Gaziantep & Syria & 39 & Nazareth & M & Israel/Adana & Syria \\
\hline 5 & Atli & $\mathrm{M}$ & Gaziantep & Turkey & 40 & Ohadi & $\mathrm{F}$ & Iran/Gaziantep & Iran \\
\hline 6 & Beyazben & F & Gaziantep & Turkey & 41 & Peters & $\mathrm{M}$ & Spain/Gaziantep & Iran \\
\hline 7 & Bianca & $\mathrm{F}$ & Italy/Adana & Italy & 42 & Red Aleppo & $\mathrm{F}$ & USDA/Adana & Syria \\
\hline 8 & Bilgen & $\mathrm{F}$ & Iran/Sanliurfa & Iran & 43 & Sefidi & $\mathrm{F}$ & Iran/Gaziantep & Iran \\
\hline 9 & Cakmak & $\mathrm{F}$ & Gaziantep & Turkey & 44 & Selection-1 & $\mathrm{F}$ & Gaziantep & Turkey \\
\hline 10 & Degirmi & $\mathrm{F}$ & Gaziantep & Turkey & 45 & Selection-2 & $\mathrm{F}$ & Gaziantep & Turkey \\
\hline 11 & Elci & $\mathrm{F}$ & Sanliurfa & Turkey & 46 & Selection-3 & $\mathrm{F}$ & Gaziantep & Turkey \\
\hline 12 & Gialla & $\mathrm{F}$ & Italy/Adana & Italy & 47 & Selection-4 & $\mathrm{F}$ & Gaziantep & Turkey \\
\hline 13 & Hacireso & $\mathrm{F}$ & Sanliurfa & Turkey & 48 & Selection-5 & $\mathrm{F}$ & Gaziantep & Turkey \\
\hline 14 & Haciserifi & $\mathrm{F}$ & Iran/Gaziantep & Iran & 49 & Selection-6 & $\mathrm{F}$ & Gaziantep & Turkey \\
\hline 15 & Halebi & $\mathrm{F}$ & Gaziantep & Turkey & 50 & Selection-7 & $\mathrm{F}$ & Gaziantep & Turkey \\
\hline 16 & Kalehgouchi & $\mathrm{F}$ & Iran/Gaziantep & Iran & 51 & Selection-8 & $\mathrm{F}$ & Gaziantep & Turkey \\
\hline 17 & Kaska & $\mathrm{M}$ & Gaziantep & Turkey & 52 & Selection-9 & $\mathrm{F}$ & Gaziantep & Turkey \\
\hline 18 & Kerman-1 & $\mathrm{F}$ & Spain/Gaziantep & Iran & 53 & Selection-10 & $\mathrm{F}$ & Gaziantep & Turkey \\
\hline 19 & Kerman-2 & $\mathrm{F}$ & Israel/Adana & Iran & 54 & Selection-11 & $\mathrm{F}$ & Gaziantep & Turkey \\
\hline 20 & Ketengomlek & $\mathrm{F}$ & Gaziantep & Turkey & 55 & Selection-12 & $\mathrm{F}$ & Gaziantep & Turkey \\
\hline 21 & Kirmizi-1 & $\mathrm{F}$ & Adana & Turkey & 56 & Selection-13 & $\mathrm{F}$ & Gaziantep & Turkey \\
\hline 22 & Kirmizi-2 & $\mathrm{F}$ & Gaziantep & Turkey & 57 & Selection-14 & $\mathrm{F}$ & Gaziantep & Turkey \\
\hline 23 & Kirmizi-3 & $\mathrm{F}$ & Sanliurfa & Turkey & 58 & Selection-15 & $\mathrm{F}$ & Gaziantep & Turkey \\
\hline 24 & Larnaka & $\mathrm{F}$ & Israel/Adana & Cyprus & 59 & Selection-16 & $\mathrm{F}$ & Gaziantep & Turkey \\
\hline 25 & M3 & M & Italy/Adana & Syria & 60 & Sfax & $\mathrm{F}$ & USDA/Adana & Tunusia \\
\hline 26 & M7 & $\mathrm{M}$ & Italy/Adana & Syria & 61 & Siirt & $\mathrm{F}$ & Gaziantep & Turkey \\
\hline 27 & Male-1 & $\mathrm{M}$ & Sanliurfa & Turkey & 62 & Siirt-85 & $\mathrm{F}$ & Sanliurfa & Turkey \\
\hline 28 & Male-7 & $\mathrm{M}$ & Sanliurfa & Turkey & 63 & Siirt-88 & $\mathrm{F}$ & Sanliurfa & Turkey \\
\hline 29 & Male-12 & $\mathrm{M}$ & Sanliurfa & Turkey & 64 & Siirt-91 & $\mathrm{F}$ & Sanliurfa & Turkey \\
\hline 30 & Male-13 & $\mathrm{M}$ & Sanliurfa & Turkey & 65 & Sultani & $\mathrm{F}$ & Gaziantep & Turkey \\
\hline 31 & Male-16 & M & Sanliurfa & Turkey & 66 & Uygur & M & Gaziantep & Turkey \\
\hline 32 & Male-18 & $\mathrm{M}$ & Sanliurfa & Turkey & 67 & Uzun & $\mathrm{F}$ & Gaziantep & Turkey \\
\hline 33 & Male-23 & $\mathrm{M}$ & Sanliurfa & Turkey & 68 & Vahidi & $\mathrm{F}$ & Iran/Gaziantep & Iran \\
\hline 34 & Male-25 & M & Sanliurfa & Turkey & 69 & White Oleimy & $\mathrm{F}$ & Spain/Adana & Syria \\
\hline 35 & Manisa-1 & M & Adana & Turkey & & & & & \\
\hline
\end{tabular}

$\mathrm{F}=$ female; $\mathrm{M}=$ male.

yThe first location refers to the source of budwood materials and the second refers to the germplasm where the budwoods were grafted and the leaf sampling was done for this study.

There are several microsatellite techniques and among them simple sequence repeats (SSRs) were used to identify 17 pistachio cultivars using their nuts collected from the markets in the U.S. and in Europe (Ahmad et al., 2003). Another molecular technique based on microsatellite loci is ISSRs, which are based on the amplification of regions between inversely oriented, closely spaced microsatellites. The major advantage of this method is the fact that it does not require a time-consuming and expensive step of genomic or other library construction. ISSRs are mostly inherited as dominant markers and are random type markers (Zietkiewicz et al., 1994).

In this study, we attempt to 1) set up and use first ISSR technique in pistachio cultivar identification; 2) characterize a broad range of pistachio germplasm originating from seven countries by RAPD, ISSR, and AFLP analysis; 3) compare the three molecular marker techniques in the discrimination of pistachio genotypes and determination of relationships among them; 4) determine the origins of previously selected pistachio genotypes; and 5) investigate whether some pistachio cultivars with the same identity in different germplasm collections have the same DNA fingerprints.

\section{Materials and Methods}

Plant materials and DNA extraction. Leaf samples of 69 pistachio genotypes (52 females and 17 males) were collected from three different pistachio germplasm collections in Turkey: University of Cukurova in Adana (15), Pistachio Research Institute in Gaziantep (38), and Ceylanpinar State Farm in Sanliurfa (16) Provinces (Table 1). Origins of the 69 pistachio genotypes were Cyprus, Greece, Iran, Italy, Syria, Tunisia, and Turkey. The collected leaf samples were washed and dried, then frozen in liquid nitrogen until use. Genomic DNA was extracted from leaf tissue by the CTAB method of Doyle and Doyle (1987) with minor modifications (Kafkas and Perl-Treves, 2002). Concentration of extracted DNA was estimated by comparing band intensity with $\lambda$ DNA of known concentrations, after $0.8 \%$ agarose gel electrophoresis and ethidium bromide staining. DNA was diluted 
to $5 \mathrm{ng} \cdot \mu \mathrm{L}^{-1}$ for RAPD and ISSR analysis, and $25 \mathrm{ng} \cdot \mu \mathrm{L}^{-1}$ for AFLP reactions.

RAPD, ISSR, AND AFLP REACTIONS. RAPD reactions were performed according to Williams et al. (1990) and ISSR reactions were done according to Zietkiewicz et al. (1994) with minor modifications. Amplification reactions in both techniques were carried out in a $25-\mu \mathrm{L}$ volume containing $75 \mathrm{~mm}$ Tris- $\mathrm{HCl}, \mathrm{pH} 8.8,20 \mathrm{~mm}\left(\mathrm{NH}_{4}\right)_{2} \mathrm{SO}_{4}$, $2.0 \mathrm{~mm} \mathrm{MgCl}_{2}, 0.1 \%$ Tween 20, $0.2 \mu \mathrm{M}$ primer, $100 \mu \mathrm{M}$ each of dATP, dGTP, dCTP and dTTP, 1 unit of Taq DNA polymerase and $10 \mathrm{ng}$ of genomic DNA.

PCR amplifications were performed in a gradient thermal cycler (Eppendorf, Hamburg, Germany). The RAPD program included 1 cycle of 2 min at $94^{\circ} \mathrm{C}$, followed by 35 cycles of $45 \mathrm{~s}$ at $94{ }^{\circ} \mathrm{C}, 1 \mathrm{~min}$ at 36 ${ }^{\circ} \mathrm{C}$, and 2 min at $72{ }^{\circ} \mathrm{C}$, followed by a final incubation for $5 \mathrm{~min}$ at $72{ }^{\circ} \mathrm{C}$. In ISSR, the thermal cycler was programmed to 1 cycle of 3 min at $94^{\circ} \mathrm{C}$, followed by 40 cycles of $1 \mathrm{~min}$ at $94{ }^{\circ} \mathrm{C}, 1 \mathrm{~min}$ at 40 to $60^{\circ} \mathrm{C}$ (depending upon primer), and $2 \mathrm{~min}$ at $72^{\circ} \mathrm{C}$, followed by a final incubation for $7 \mathrm{~min}$ at 72 ${ }^{\circ} \mathrm{C}$. RAPD and ISSR amplification products were analyzed by gel electrophoresis in $1.8 \%$ agarose in $1 \times$ TBE buffer, stained with ethidium bromide and photographed under ultraviolet light.

AFLP analysis was performed according to Vos et al. (1995) with minor modifications (Kafkas et al., 2005). The adaptor sequences, preselective amplification primers and selective primers are listed in Table 2 . The PCR reactions for all marker types were conducted in duplicate.

Primer Selection. To find optimum annealing temperatures (Ta) of ISSR primers, first, melting temperatures of each primer were calculated according to the $\mathrm{Tm}=[2(\mathrm{~A}+\mathrm{T})+4(\mathrm{G}+\mathrm{C})]$ formula (Wallace et al., 1979) and then, the optimum Ta of each ISSR primer was determined by doing PCR reactions in four pistachio genotypes using the gradient thermal cycler with the gradient set to $\mathrm{Tm} \pm 5$ or \pm 10 .

Initially, 100 ISSR primers [University of British Columbia (UBC), Vancouver, B.C., Canada (set no. 9)], 180 RAPD primers [100 from UBC set no. 4 and 80 (sets A, D, R, and AA) from Operon Technologies, Alameda, Calif.], and 25 AFLP primer combinations were tested with seven pistachio cultivars for PCR amplification. On the basis of the maximum number of reproducible and distinctly scorable polymorphic bands, 20 ISSR primers, 20 RAPD primers, and six AFLP primer pairs were selected for the characterization of 69 pistachio genotypes.

BAND SCORING AND DATA ANALYSIS. RAPD, ISSR, and AFLP bands were scored manually as present (1) or absent (0). Only the clearest and strongest reproducible bands were scored and used for the analysis. The ability of the most informative primers or primer pairs to differentiate between the genotypes was assessed by calculating their resolving power (Rp) according to Prevost and Wilkinson (1999) using the formula $\mathrm{Rp}=\sum \mathrm{Ib}$, where $\mathrm{Ib}=1-(2 \times|0.5-\mathrm{p}|)$, and $\mathrm{p}$ is the proportion of the 69 genotypes containing the I band. The polymorphism information content (PIC) of each marker was calculated using PIC = $1-\sum \mathrm{Pi}^{2}$ where $\mathrm{Pi}$ is the band frequency of the $\mathrm{i}^{\text {th }}$ allele (Smith et al., 1997). To obtain a measure of the utility of the marker systems, effective multiplex ratio (EMR) and marker index (MI) were also calculated (Powell et al., 1996). EMR is defined as the number of bands ( $n$ ) analyzed per primer (in RAPD and ISSR analysis) or primer combination (in AFLP analysis) multiplied by the percentage of polymorphic loci $\left(P_{0.95} ;\right.$ EMR $\left.=\mathrm{n} P_{0.95}\right)$. MI was defined as the product of the average polymorphism information content for the polymorphic bands and EMR for each marker system.

Phylogenetic analysis using parsimony (PAUP) 4.0b package software (Swofford, 1998) was used to generate a mean character differences matrix and a Nei and Li (1979) distance matrix to produce dendrograms using the UPGMA. Bootstrap values were obtained with the UPGMA option based on 500 replicates. The Jaccard similarity matrix was also calculated using numerical taxonomy and multivariate analysis system (NTSYSpc) $2.11 \mathrm{~V}$ package software (Rohlf, 2004).

The correspondence between pairs of matrices obtained from the three marker systems was tested with Mantel cophenetic correlation analysis (Mantel, 1967). Comparisons were done using both mean character difference matrix and Nei and Li (1979) distance matrix. The Mantel test was also applied to compare the two different matrices in each marker system.

\section{Results and Discussion}

LEVELS OF POLYMORPHISM AND DISCRIMINATING CAPACITY OF THE ASSAYs. The results of three molecular assays in fingerprinting the 69 pistachio cultivars are given in Table 3. In RAPD analysis, the chosen 20 primers produced a total of 147 scorable bands, an average of 7.35 bands per primer, of which 69 (46.9\%) were polymorphic (Table 3 ). The number of total bands ranged from five to 11 and the number of polymorphic bands varied between one and six (average 3.45). Hormaza et al. (1994a) obtained $25 \%$ polymorphism and 9.9 total and 2.65 polymorphic bands in the characterization of 15 pistachio cultivars by RAPD. In a study reported by Barazani et al. (2003) in the characterization of Turkmen pistachio populations, eight RAPD primers produced 62 total bands (average 7.75 ) and $43.5 \%$ of them were polymorphic (average 3.38). Our results were similar to those of Barazani at al. (2003) and had higher rates than those of Hormaza et al. (1994a). 
Table 3. Comparison of AFLP, ISSR, and RAPD marker systems in fingerprinting of 69 pistachio genotypes.

\begin{tabular}{llccc}
\hline & Acronym & AFLP & ISSR & RAPD \\
\hline $\begin{array}{llcc}\text { Primers or primer pairs } \\
\quad \text { no.) }\end{array}$ & NP & 6 & 20 & 20 \\
Total bands (no.) & NB & 269 & 156 & 147 \\
Bands per assay (no.) & NBA & 44.8 & 7.8 & 7.35 \\
Polymorphic bands (no.) & NPB & 165 & 73 & 69 \\
Polymorphic bands per & & & & \\
$\quad$ assay (no.) & NPA & 27.5 & 3.65 & 3.45 \\
Monomorphic bands (no.) & NMB & 104 & 83 & 78 \\
Monomorphic bands per & & & & \\
$\quad$ assay (no.) & NMA & 17.3 & 4.15 & 3.9 \\
Polymorphism (\%) & PP & 61.3 & 46.2 & 46.9 \\
Resolving power & Rp & 164.4 & 53.62 & 49.51 \\
Polymorphism & & & & \\
$\quad$ information content & PIC & 0.607 & 0.750 & 0.773 \\
Effective multiplex ratio & EMR & 27.49 & 3.65 & 3.45 \\
Marker index & MI & 16.69 & 2.74 & 2.66 \\
\hline
\end{tabular}

This may be explained by our use of quadruple the number of plant samples than used by Hormaza et al. (1994a).

In ISSR, a total of 156 bands were amplified by the 20 primers, an average of 7.7 bands per primer, of which $73(46.2 \%)$ were polymorphic (Table 3 ). The total number of amplified fragments was between five and 11 and the number of polymorphic fragments ranged from two to seven. This study reports the first application of the ISSR technique in pistachio and reveals its usefulness in this species. The ISSR technique produced more reproducible bands than RAPD in accordance with previous studies applied in different plant species (Goulao et al., 2001; Mattioni et al., 2002). During the ISSR screening in this study, good amplification products were obtained from primers based on GA, CA, and CT repeats. $(\mathrm{AT})_{\mathrm{n}}$ primers gave no amplification products, although $(\mathrm{AT})_{\mathrm{n}}$ dinucleotide repeats are thought to be the most abundant motifs in the plant kingdom (Morgante and Olivieri, 1993). Similar results were also reported by Casasoli et al. (2001) in chestnut (Castanea sativa Mill.), Nagaoka and Ogihara (1997) in wheat (Triticum spp.), Kim et al. (2002) in sesame (Sesamum indicum L.), and Moreno et al. (1998) in grapevine (Vitis vinifera L.). Selfannealing of ISSR primers based on AT motifs due to sequence complementarity is a possible explanation for these results (Blair et al., 1999). The present work has shown that ISSR-PCR analysis is quick, and generates sufficient polymorphisms to have potential for large-scale DNA fingerprinting purposes.

In AFLP, six primer combinations generated a total of 269 fragments, an average of 27.5 bands per primer pair, of which $165(61.3 \%)$ were polymorphic (Table 3$)$. The number of total fragments among primer combinations varied from 30 to 73 and the number of polymorphic bands ranged from 19 to 49 .

The Rp was obtained with AFLP, which had a much greater value than ISSR and RAPD (Table 3). There was a slight difference between RAPD and ISSR in their Rp values. PIC was higher in RAPD and ISSR than AFLP and the former markers had similar values as for their $R p$ values.

Resolving power has been found to correlate strongly with its ability to distinguish between genotypes. It is usually difficult to compare the value of primers used in different investigations. The use of Rp might enable direct comparison of primers both within and between studies. The function is well suited for comparing primers, primer combinations generated by RAPD, ISSR, and
AFLP analysis. It can also be used to predict the performance of groups of primers (Prevost and Wilkinson, 1999). In AFLP analysis of this study, $\mathrm{Rp}$ values of the primer combinations ranged from $20.75\left(\mathrm{E}_{\mathrm{AAG}} / \mathrm{M}_{\mathrm{CTA}}\right)$ to $48.93\left(\mathrm{E}_{\mathrm{AGC}} / \mathrm{M}_{\mathrm{AAT}}\right)$. For ISSR primers, Rp ranged from 0.12 (UBC826) to 8.09 (UBC817) and Rp of RAPD primers varied from 0.41 (UBC361) to 8.20(OPR03; data not shown).

Powell et al. (1996) introduced the concept of $\mathrm{Ml}$ as an overall measure of marker efficiency in detecting polymorphisms. In this study, the highest EMR and MI were in AFLP, followed by ISSR and RAPD (Table 3). The high value of the MI for AFLPs is the result of a very high multiplex ratio, and highlights the distinctive nature of these markers.

As mentioned, AFLP had the highest EMR + MI values and followed by ISSR and RAPD, respectively (Table 3). The higher level of polymorphism detected in pistachio cultivars by AFLP markers than with RAPDs and ISSRs highlights the discriminating capacity of the AFLPs. This result agrees with previous studies where AFLPs were compared to RAPDs and ISSRs (Lanham et al., 2000; McGregor et al., 2000; Patzak, 2001; Talhinhas et al., 2003). Therefore, AFLPs are preferable to RAPDs and ISSRs for pistachio cultivar identification and plant certification.

There were only slight differences between ISSR and RAPD in the comparison of EMR and MI. In RAPD analysis, the problems of reliability and repeatability among laboratories should be taken into consideration (Belaj et al., 2003). We suggest that reliable RAPD data can be generated by the replication of amplification reactions at least two or three times and by careful band selection. The above-mentioned problems for RAPDs limit their use in DNA fingerprinting. ISSR seems to be better technique than RAPD because of higher reproducibility.

There are several molecular techniques available to assess genetic variability of plant cultivars and individuals. Reproducibility, cost, speed, and the ability to detect genetic variation between genotypes mainly determine their utility in germplasm characterization. The results presented here show that RAPD, ISSR and AFLP markers are able to reveal variability between pistachio cultivars and genotypes. AFLP is the best technique among them. ISSR and AFLP assays are more reliable than RAPD because of their reproducible bands, and ISSR is preferred over RAPD, where financial investment and technical knowledge are limited.

CORRELATIONS BETWEeN MARKER SYSTEMS BASED ON GENETIC DISTANCE ESTIMATES. A comparison of the genetic distances obtained with the three types of molecular markers was made. The mantel matrix correspondence test was used to compare the genetic distances calculated according to the mean character difference and Nei and Li (1979) genetic distance. The correlation coefficients (Table 4) were statistically significant for all three molecular markers. The correlation coefficients of genetic distances

Table 4. Mantel matrix correspondence test between AFLP, ISSR, and RAPD marker systems used in fingerprinting of 69 pistachio cultivars according to the Nei and Li genetic distance (above diagonal) and the mean character difference (below diagonal) calculated by PAUP program. Coefficients in bold are Mantel matrix correspondence test between Nei and Li genetic distance and mean character difference.

\begin{tabular}{lccc}
\hline & RAPD & ISSR & AFLP \\
\hline RAPD & $\mathbf{0 . 9 9 6}$ & 0.578 & 0.694 \\
ISSR & 0.599 & $\mathbf{0 . 9 9 8}$ & 0.697 \\
AFLP & 0.726 & 0.696 & $\mathbf{0 . 9 9 7}$ \\
\hline
\end{tabular}


resulting between ISSR and RAPD data were, however, lower than those obtained with the other pairs of markers, whereas the value between RAPD and AFLP was the highest. Patzak (2001) found a very high correlation (over 0.93 ) between RAPD, ISSR, and AFLP markers in hop (Humulus lupulus L.). Virk et al. (2000) compared these three marker systems by using rice (Oryza sativa L.) germplasm and reported that the correlation was high between AFLP and RAPD (0.77), low between RAPD and ISSR (0.22), and intermediate between ISSR and AFLP (0.42). Lanham et al. (2000) also found very low (0.43) correlation between RAPD and ISSR in Ribes nigrum L. In a study performed by Yue et al. (2002), genetic similarity values estimated from three systems (RAPD, AFLP, and ISSR) showed only a slight correlation (0.19-0.22), suggesting that different marker systems may selectively screen complementary, rather than overlapping regions of the arowana (Scleropages formosus Muller and Schlegel) genome.

When we compare correlation coefficient values between our study and the literature, our values were intermediate. We should consider that the type of genetic polymorphism detected by the three marker systems, the number of primers used as well as plant species analyzed, may also affect the correlations among different markers. The correlation coefficients between two distance matrices were also significant and had very high coefficient values, as expected; however, the values were higher when we used Nei-Li distances than mean character difference.

Clustering of Pistachio Cultivars/GenotyPes. The general UPGMAdendrogram (Fig. 1) constructed using the combined data of the three sets of molecular markers was very similar to those obtained separately with each marker (data not shown). However, there were some differences, which led to a better representation of the relationships for most of the cultivars, according to their geographic area of diffusion.

Two main clusters were observed: pistachio cultivars originating from Iran were in the first cluster, whereas the cultivars originating from the other countries such as Turkey and Syria were in the second cluster. A branch of 78 bootstrap replicates separated 19 cultivars originating from Iran from the second cluster and a branch of 80 bootstrap replicates separated the second cluster from others. Therefore, the first cluster was named the "Iranian" and second cluster was named the "Mediterranean." In a study performed by Hormaza et al. (1994a), 15 pistachio cultivars originating from Iran, Syria, Italy, Tunisia, Greece, and Azerbaijan were characterized by using 14 polymorphic RAPD primers. The pistachio cultivars that were analyzed by Hormaza et al. (1994a) separated into two clusters by UPGMA analysis. One, the "Mediterranean" cluster, comprised cultivars obtained from the Mediterranean region of Europe, northern Africa, and the Middle East. The second cluster, the "Iranian-Caspian," comprised cultivars obtained from east of the Zagros Mountains. Therefore, our study of a larger set of pistachio germplasm supports the previous report.

In contrast to Hormaza et al. (1994a), in this study the second cluster divided into three main subclusters and a branch of 80 bootstrap replicates separated the second cluster from the others: the first subcluster (named the "Siirt" subcluster) included 'Siirt' and some other female selections and a branch of 81 bootstrap replicates separated second subcluster from the others; the second subcluster (named the "Turkish" subcluster) contained major cultivars in production in Turkey such as 'Kirmizi' and 'Uzun' and a branch of 66 bootstrap replicates separated "Turkish" subcluster from the third one. The third subcluster (named the
"Syrian" subcluster) consisted of Syrian, Greece, Italian, Cyprus, and North African cultivars. Thus, the pistachio genotypes were separated according to their geographic area of diffusion.

These findings reveal new understanding in the diffusion of pistachio cultivation from its center of origin, the Iranian-Caspian region, via southeastern Turkey to Syria, Mediterranean region of Europe, and North Africa. According to Hormaza et al. (1994a), there are two centers of diversity of $P$. vera: one extends from Crimea to the Caspian Sea and the second comprises the Mediterranean region of Europe, northern Africa, and the Middle East. The authors noted that the Syrian pistachios have a local origin rather than being derived from ancient Iranian germplasm. The only evidence the authors use to support this hypothesis is the reported findings of pistachio nuts from excavations in Neolithic settlements in Syria. Contrary to these results, our study indicates that the diffusion of pistachio cultivation is from Iranian origin via southeastern Turkey to Syria and the other countries.

Hormaza et al. (1994a) stated that pistachio was imported from Syria into Italy during the time of the Roman Empire, based on historical records, and its culture was expanded to the Mediterranean, North Africa, and the Middle East countries. Our UPGMA dendrogram and bootstrap analysis are in accordance with their results by grouping Syrian and Italian cultivars in the same subcluster.

In this study, seven male genotypes were distinct from the two main clusters, and were separated into two outgroups: a branch of 100 bootstrap replicates separated 'Manisa-1', 'Manisa-2', 'Atli', and 'Uygur' male genotypes from the two major groups and a branch of 93 bootstrap replicates separated 'Male-12', 'Male-13', and 'Male-16' from the rest of the pistachio genotypes. The latter two groups may be hybrids between $P$. vera and wild Pistacia species (based on unpublished observation). These groups were, therefore, named "Outgroup-1" and "Outgroup-2."

According to the clustering of 69 pistachio cultivars and genotypes, genetic distances (Nei and Li) and similarities (Jaccard) were also calculated and are shown in Table 5. The closest subcluster to "Iranian" cluster was "Siirt," and "Turkish" with "Syrian" groups followed it by having similar distances and similarities. "Outgroup-1" and "Outgroup-2" were the most distant groups to "Iranian" cluster. The similarities and distances of "Siirt" subcluster to "Turkish" and "Syrian" subclusters, and 'Turkish' to "Syrian" were similar. "Outgroup-1" was closer to Turkish subcluster than "Outgroup-2." The closeness of the clusters was "Iranian" - "Siirt" - "Turkish" / "Syrian" - "Outgroup-1" - "Outgroup-2."

Genetic distances and similarities within clusters were also calculated and may show diversity level within the groups. The diversity within groups from low to high was in "Outgroup-1," "Siirt," "Turkish," "Syrian," "Iranian," and “Outgroup-2," respectively (Table 5). Hormaza et al. (1994a) considered the pistachio cultivars in the Mediterranean cluster with a lower genetic diversity than Iranian one. Ahmad et al. (2003) described a wider genetic base for "Syrian" samples than for "Iranian" samples by SSR analysis. Contrary to the previous studies, our study showed that genetic similarities within "Iranian" and "Mediterranean" clusters, and within Syrian cultivars are very similar (0.88). "Turkish" subcluster had only a higher genetic similarity (0.92) than the others. This is probably because of a narrow genetic base for the "Turkish" subcluster originating from only the Gaziantep Province of Turkey.

When we consider all above results based on clustering of pistachio cultivars, the "Siirt" subcluster, especially the cultivars 
Fig. 1. Dendrogram of 69 pistachio cultivars and genotypes using the unweighted pair group method with arithmetic averages (UPGMA). The database included 269 AFLP, 156 ISSR, and 147 RAPD bands. UPGMA analysis was conducted by phylogenetic analysis using parsimony (PAUP) software using Nei and Li (1979) distance. Numbers indicate the percentage of 500 bootstrap replicates that included a given node.

(1)

(1)
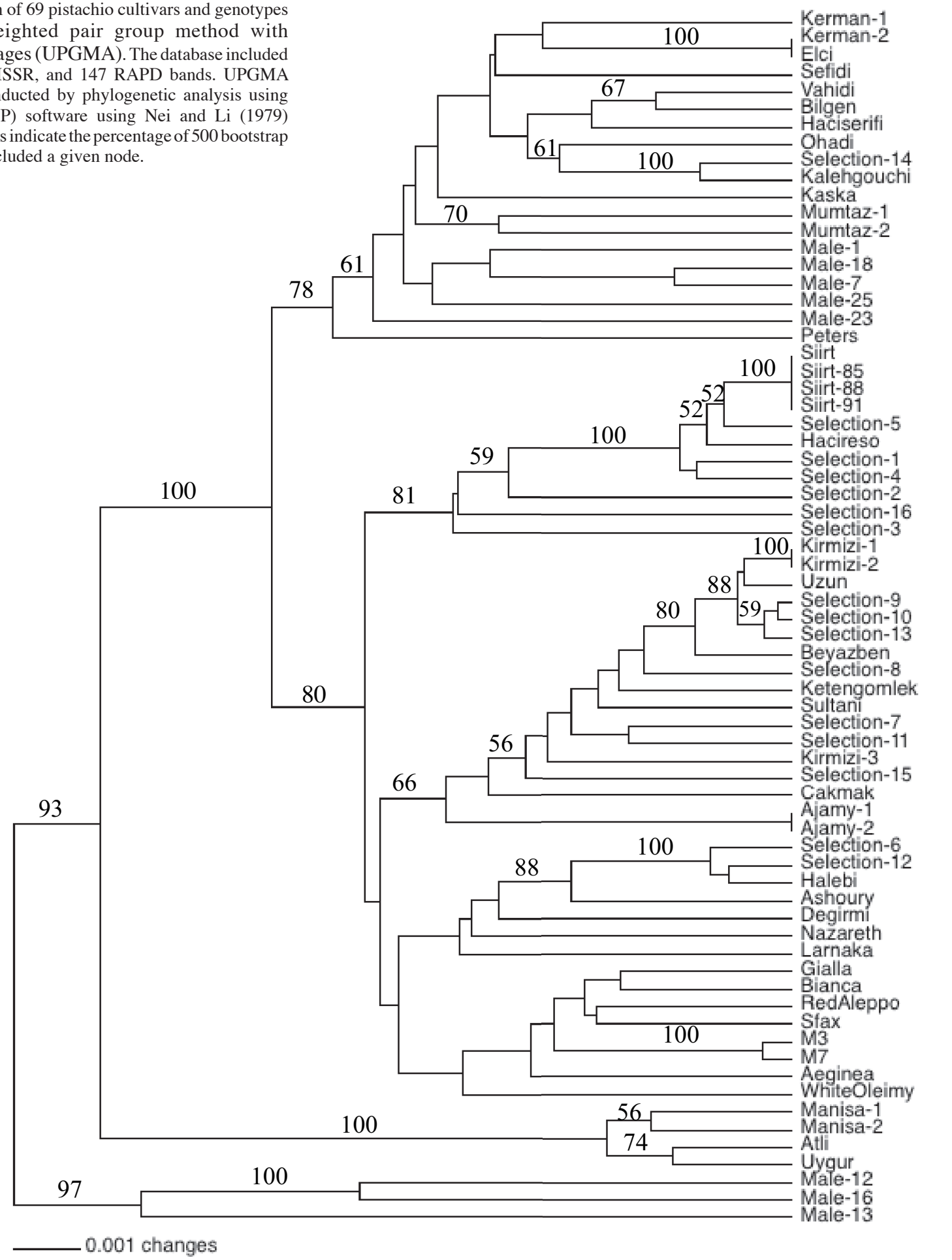

Table 5. Genetic similarities based on Jaccard matrix (above diagonal) and genetic distances based on mean character difference (below diagonal) between groups of pistachio genotypes clustered in the UPGMA dendrogram using combined data of AFLP, ISSR, and RAPD marker systems in characterization of 69 pistachio genotypes.

\begin{tabular}{lllllll}
\hline Genotype group & Iranian & Siirt & Turkish & Syrian & Outgroup-1 & Outgroup-2 \\
\hline Iranian & $\mathbf{0 . 8 8 0}(\mathbf{0 . 1 1 0})$ & 0.847 & 0.828 & 0.831 & 0.762 \\
Siirt & 0.144 & $\mathbf{0 . 9 3 3}(\mathbf{0 . 0 6 0 )}$ & 0.861 & 0.858 & 0.769 \\
Turkish & 0.166 & 0.130 & $\mathbf{0 . 9 2 2}(\mathbf{0 . 0 7 0})$ & 0.864 & 0.782 & 0.822 \\
Syrian & 0.162 & 0.133 & 0.127 & $\mathbf{0 . 8 9 0}(\mathbf{0 . 1 0 1})$ & 0.783 \\
Outgroup-1 & 0.238 & 0.218 & 0.172 & 0.216 & 0.774 \\
Outgroup-2 & 0.242 & 0.234 & 0.228 & 0.240 & $\mathbf{0 . 9 4 1}(\mathbf{0 . 0 5 1 )}$ & 0.742 \\
\hline
\end{tabular}


Siirt and Hacireso, presents important information about the diffusion of pistachio cultivation. This subcluster may be considered as a transition cluster from "Iranian" to "Mediterranean." The origin of the 'Hacireso' is Uludere County of Hakkari Province in Turkey, which has a border with northeastern Iran and northern Iraq. This cultivar had been brought to Siirt Province in 1933 by Semdin Avci (A.M. Bilgen, personal communication). The origin of the cultivar Siirt had always been an open question, and it was assumed to have an Iranian origin because of its nut characteristics. However, the resulting dendrogram in this paper showed that the cultivar Siirt is separated from the "Iranian" cluster and is closely related to the cultivar Hacireso. Therefore, 'Siirt' may have the same origin as 'Hacireso', or it may be a descendant of it. Currently, the cultivar Siirt is productive and increasingly important, especially in Siirt Province, and in the other provinces of Turkey, where pistachio production is mostly done by grafting onto wild Pistacia trees [especially P. eurycarpa Yalt. (Kafkas and Perl-Treves, 2001)]. Fingerprinting of more samples from these areas could verify this hypothesis.

GeNetic RELATIONSHIPS AMONG PISTACHIO CULTIVARS/GENOTYPES. In all the assays, some pairs of samples ('Kerman-2'-'Elci', 'Siirt'-'Siirt-85'-'Siirt-88'-'Siirt-91', 'Kirmizi-1'-'Kirmizi-2', and 'Ajamy-1'-'Ajamy-2') could not be separated and remained identical genotypes. The cultivar Kerman has significant production, especially in U.S. (Ferguson, 1995). In this study, the samples of cultivars Elci and Kerman-2 from Israel could not be separated; however, they slightly differed from 'Kerman-1' of Spain. After communicating with scientists in Turkey, we learned that 'Elci' was introduced from Israel to Ceylanpinar State Farm in Sanliurfa (S. Elci, personal communication) and was named 'Elci' by the grafter. Our results show that the introduced material from Israel is 'Kerman'. However, a question was raised with identification of the 'Kerman-1' sample from Spain, which was closely related to other 'Kerman' samples. Further study is necessary to explain this question.

In the "Iranian" cluster, 'Kalehghouchi' and 'Selection-14', 'Kalehghouchi' and 'Ohadi', 'Bilgen' and 'Vahidi', 'Male-7' and 'Male-18' were the closest pairs of cultivars. Ohadi is the major cultivar in the pistachio production of Iran, accounting for $60 \%$ to $70 \%$ of Iranian production. The cultivar Kalehghouchi is also important in Iran (Sheibani, 1995). The cultivars Vahidi, Haciserifi, Mumtaz, and Sefidi were good cultivars 50-60 years ago (Whitehouse, 1957), but they are now only genetic resources. Among introduced cultivars from Iran, only the cultivar Ohadi formed a very small place in the pistachio production of Turkey, especially in Ceylanpinar State Farm in Sanliurfa, where there are over 3000 ha.

In the "Siirt" subcluster, there was no polymorphism among the genotypes Siirt, Siirt-85, Siirt-88, and Siirt-91. Ahmad et al. (2003) used two samples of the cultivar Siirt ('Siirt a' and 'Siirt b') in their study and found no polymorphism by SSR analysis. The genotypes Siirt-85, Siirt-88, and Siirt-91 were selected because of their larger nut size and higher yields than normal 'Siirt' in Ceylanpinar State Farm (Ak, 1998). The higher yields and larger nuts may be due to grafting them on different seedling rootstocks that may affect scion performance, rather than genetic differences of the scion. This result may elevate the importance of rootstock selection.

The cultivar Kirmizi is one of the major pistachio cultivars in Turkey and we had three samples from three different germplasm collections. There was no polymorphism between samples from Adana and Gaziantep, but both of these samples differed from the Sanliurfa sample. However, all three samples were in the same subcluster. We believe that this shows misidentification of 'Kirmizi' in the germplasm of Sanliurfa, and reveals the power of the DNA markers. In "Turkish" subcluster, the cultivars Ketengomlek, Sultani, and Beyazben are only germplasm materials and have no an economic value; however, we may find a limited number of trees from these cultivars in some of old pistachio orchards in Gaziantep Province of Turkey. 'Kirmizi', 'Uzun', and 'Halebi' are the oldest cultivars and there are more than 200-yearold pistachio trees in Anil-Battal Valley in Gaziantep Province. The cultivar Ajamy originated in Syria and we had two samples (from Syria and Spain). Although there was no polymorphism between them, it clustered with Turkish cultivars rather than Syrian ones. However, in bootstrap analysis, 'Ajamy' clustered with the "Syrian" subcluster.

In the "Syrian" subcluster, according to the UPGMA analysis, the cultivars Halebi, Ashoury, Degirmi, Nazareth, and Larnaka clustered in one group, and the cultivars Bianca, Gialla, Red Aleppo, M3, M7, Sfax, Aeginea, and White Oleimy clustered in the other group. However, the bootstrap analysis with 500 replicates did not support this grouping in the "Syrian" subcluster and remained all cultivars together (data not shown).

'Halebi' is one of the important pistachio cultivars in Turkey, especially in the Gaziantep Province and it clustered within the "Syrian" subcluster. The distance from Aleppo-Syria to Gaziantep is about $120 \mathrm{~km}$ and both provinces belonged previously to Ottoman Empire. Therefore, distribution of the budwood from one city to another was possible. The cultivar Degirmi is also found in Turkish germplasm but its origin is probably Syria according to our results. The cultivars Red Aleppo, Nazareth, Ashoury, and White Oleimy also have Syrian origin. Cypriot ('Larnaka'), Greek ('Aeginea'), Tunusian ('Sfax'), and Italian ('Gialla' and 'Bianca') cultivars were also in "Syrian" subcluster.

The cultivars Kirmizi, Uzun, and Halebi have been growing in Turkey for over 100 years, and may be the oldest ones in Turkey. 'Siirt' and 'Ohadi' are also major cultivars, but relatively new ones. Therefore, there are five main female pistachio cultivars in production. There are also some male genotypes for pollination. Among them, the genotype Atli is used for the cultivars Siirt and Kirmizi, 'Uygur' is for 'Uzun' and 'Halebi', and 'Kaska' is for 'Ohadi'. The genotype Kaska clustered with Iranian cultivars, 'Atli' and 'Uygur' were outside of these two major groups.

Knowledge of genetic variation and the genetic relationship between genotypes in pistachio germplasm is an important consideration for efficient utilization of germplasm resources. It is important also for the optimal design of plant breeding programs, for genetic map construction and quantitative trait loci (QTL) analysis. Based on the results of this study, construction of the first genetic linkage map in pistachio is under way.

\section{Literature Cited}

Ahmad, R., L. Ferguson, and S.M. Southwick. 2003. Identification of pistachio (Pistacia vera L.) nuts with microsatellite markers. J. Amer. Soc. Hort. Sci. 128:898-903.

Ak, B.E. 1998. The yield and fruit quality of Pistacia vera $\mathrm{cv}$ Siirt grown at the Ceylanpinar State Farm. Acta Hort. 470:510-515.

Barazani, O., A. Atayev, B. Yakubov, V. Kostiukovsky, K. Popov, and A. Golan-Goldhirsh. 2003. Genetic variability in Turkmen populations of Pistacia vera L. Genet. Resources Crop. Evol. 50:383-389.

Belaj, A., Z. Satovic, G. Cipriani, L. Baldoni, R. Testolin, L. Rallo, and I. Trujillo. 2003. Comparative study of the discrimining capacity of RAPD,AFLPand SSR markers and of their effectiveness in establishing 
genetic relationships in olive. Theor. Appl. Genet. 107:736-744.

Blair, M.W., O. Panaud, and S.R. Mccouch. 1999. Inter-simple sequence repeat (ISSR) amplification for analysis of microsatellite motif frequency and fingerprinting in rice (Oryza sativa L.). Theor. Appl. Genet. 98:780-792.

Browicz, K. 1988. Chorology of trees and shrubs in south-west Asia and adjacent regions. Polish Scientific Publ., Warsaw, Poland.

Casasoli, M., C. Mattioni, M. Cherubini, and F. Villani. 2001. Genetic linkage map of European chestnut (Castanea sativa Mill.) based on RAPD, ISSR and isozyme markers. Theor. Appl. Genet. 102:1190-1199.

Crane, J.C. 1974. Hermaphroditism in Pistacia. Calif. Agr. 28:3-4.

Doyle, J.J. and J.L. Doyle. 1987. A rapid isolation procedure for small quantities of fresh leaf tissue. Phytochem. Bul. J. 19:11-15.

Food and Agriculture Organization of the United Nations. 2005. FAOSTAT database. 30 Jan. 2006. <http://faostat.fao.org/faostat/form?collection $=$ Production. Crops.Primary $\&$ Domain $=$ Production $\&$ servlet $=1 \&$ hasbu $1 \mathrm{k}=0 \&$ version $=$ ext $\&$ language $=\mathrm{EN}>$.

Ferguson, L. 1995. Pistachios in California. Acta Hort. 419:169-173.

Goulao, L., T. Valdiviesso, C. Santana, and C.M. Oliveira. 2001. Comparison between phenetic characterization using RAPD and ISSR markers and phenotypic data of cultivated chestnut (Castanea sativa Mill.). Genet. Resources Crop Evol. 48:329-338.

Hormaza, J.I., L. Dollo, and V.S. Polito. 1994a. Determination of relatedness and geographic movements of Pistacia vera (Pistachio; Anacardiaceae) germplasm by RAPD analysis. Econ. Bot. 48:349-358.

Hormaza, J.I., L. Dollo, and V.S. Polito. 1994b. Identification of a RAPD marker linked to sex determination in Pistacia vera using bulked segregant analysis. Theor. Appl. Genet. 89:9-13.

Hormaza, J.I., K. Pinney, and V.S. Polito. 1998. Genetic diversity of pistachio (Pistacia vera, Anacardiaceae) germplasm based on randomly amplified polymorphic DNA (RAPD) markers. Econ. Bot. 52:78-87.

Ila, H.B., S. Kafkas, and M. Topaktas. 2003. Chromosome numbers of four Pistacia (Anacardiaceae) species. J Hort. Sci. Biotechnol. 78:35-38.

Kafkas, S., R. Perl-Treves, and N. Kaska. 2000. Unusual Pistacia atlantica Desf. (Anacardiaceae) monoecious sex types in the Yunt Mountains of the Manisa Province of Turkey. Israel J. Plant Sci. 48:277-280.

Kafkas, S. and R. Perl-Treves. 2001. Morphological and molecular phylogeny of Pistacia species in Turkey. Theor. Appl. Genet. 102:908-915.

Kafkas, S. and R. Perl-Treves. 2002. Interspecific relationships in the genus Pistacia L. (Anacardiaceae) based on RAPD fingerprinting. HortScience 37:168-171.

Kafkas, S., H. Ozkan, and M. Sutyemez. 2005. DNA polymorphism and assessment of genetic relationships in walnut (Juglans regia $\mathrm{L}$ ) genotypes based on AFLP and SAMPL markers. J. Amer. Soc. Hort. Sci. 130:585-590.

Kafkas, S. 2006. Phylogeny, evolution and biodiversity in the genus Pistacia (Anacardiaceae). In: A.K. Sharma, A. Sharma (eds) Plant genome: Biodiversity and evolution. Volume 1C: Phanerogams (Angiosperm-dicotyledons) Science Publ., Eufield, N.H. (In press).

Kaska, N. 1995. Pistachio nut growing in Turkey. Acta Hort. 419:161164 .

Katsiotis, A., M. Hagidimitriou, A. Drossou, C. Pontikis, M. Loukas. 2003. Genetic relationships among species and cultivars of Pistacia using RAPDs and AFLPs. Euphytica 132:279-86.

Kim, D.H., G.Y. Danin-Poleg, S.W. Lee, K.B. Shim, C.W. Kang, and Y. Kashi. 2002. Genetic relationships of sesame germplasm collection as revealed by inter-simple sequence repeats. Plant Breeding 121:259-262.

Lanham, P.G.,A. Korycinska, and R.M. Brennan. 2000. Genetic diversity within a secondary gene pool for Ribes nigrum L. revealed by RAPD and ISSR markers. J. Hort. Sci. Biotechnol. 75:371-375.

Maggs, D.H. 1973. Genetic resources in pistachio. Plant Genet. Res. Nwsl. 29:7-15.

Mantel, N. 1967. The detection of disease clustering and generalized regression approach. Cancer Res. 27:209-220.

Mattioni, C., M. Casasoli, M. Gonzalez, R. Ipinza, and F. Villani. 2002.
Comparison of ISSR and RAPD markers to characterize three Chilean Nothofagus species. Theor. Appl. Genet. 104:1064-1070.

McGregor, C.E., C.A. Lambert, M.M. Greyling, J.H. Louw, and L. Warnich. 2000. A comparative assessment of DNA fingerprinting techniques (RAPD, ISSR, AFLP and SSR) in tetraploid potato (Solanum tuberosum L.) germplasm. Euphytica 113:135-144.

Moreno, S., J.P. Martin, and J.M. Ortiz. 1998. Inter-simple sequence repeat PCR for characterization of closely related grapevine germplasm. Euphytica 101:117-125.

Morgante, M. and A.M. Olivieri. 1993. PCR-amplified microsatellites as markers in plant genetics. Plant J. 3:175-182.

Nagaoka, T. and Y. Ogihara. 1997. Applicability of inter-simple sequence repeat polymorphisms in wheat for use as DNA markers in comparison to RFLP and RAPD markers. Theor. Appl. Genet. 94:597-602.

Nei, M. and W. Li. 1979. Mathematical model for study genetic variation in terms of restriction endonucleases. Proc. Natl. Acad. Sci. USA 74:5267-5273.

Ozbek, S. and M. Ayfer. 1958. An hermaphrodite Pistacia found in the vicinity of Antep, Turkey. Proc. Amer. Soc. Hort. Sci. 72:240-241.

Patzak, J. 2001. Comparison of RAPD, STS, ISSR and AFLP molecular methods used for assessment of genetic diversity in hop (Humulus lupulus L.). Euphytica 121:129-18.

Powell, W.M., M. Morgante, C. Andre, M. Hanafey, J. Vogel, S. Tingey, and A. Rafalski. 1996. The comparison of RFLP, RAPD, AFLP and SSR (microsatellite) markers for germplasm analysis. Mol. Breeding 2:225-238.

Prevost, A. and M.J. Wilkinson. 1999. A new system of comparing PCR primers applied to ISSR fingerprinting of potato accessions. Theor. Appl. Genet. 98:107-112.

Rohlf, J.F. 2004. NTSYS-pc: 2.11 Numerical taxonomy and multivariate analysis system. Exeter Software, Setauket, N.Y.

Shebani, 1995. Pistachio production in Iran. Acta Hort. 419:165-168.

Smith, J.S.C., E.C.L. Chin, H. Shu, O.S. Smith, S.J. Wall, M.L. Senior, S.E. Mitchel, S. Kresorich, and J. Tiegle. 1997. An evaluation of the utility of SSR loci as molecular marker in maize (Zea mays): Comparisons with data from RFLP and pedigree. Theor. Appl. Genet. 95:163-173.

Swofford,D.L, 1998. PAUP: Phylogenetic analysis using parsimony (and other methods). Version 4. Sinauer Assoc., Sunderland, Mass.

Talhinhas, P., J. Neves-Martins, and J. Leitao. 2003. AFLP, ISSR and RAPD markers reveal high levels of genetic diversity among Lupinus spp. Plant Breeding 122:507-510.

Virk, P.S., J. Zhu, H.J. Newbury, G.J. Bryan, M.T. Jackson, and B.V. Ford-Lloyd. 2000. Effectiveness of different classes of molecular marker for classifying and revealing variation in rice (Oryza sativa) germplasm. Euphytica 112:275-284.

Vos, P., L. Hogers, M. Bleeker, T. Van De Lee, M. Hornes, A. Frijters, J. Pot, J. Peleman, M. Kuiper, and M .Zabeau. 1995. AFLP: A new technique for DNA fingerprinting. Nucleic Acids Res. 23:4407-4414.

Wallace, R.B., J. Shaffer, R.F. Murphy, J. Bonner, T. Hirose, and K. Itakura. 1979. Hybridization of synthetic oligodeoxyribonucleotides to phi chi 174 DNA: The effect of single base pair mismatch. Nucleic Acids Res. 6:3543-3557.

Whitehouse, W.E. 1957. The pistachio nut-A new crop for the western United States. Econ. Bot. 11:281-321.

Williams, J.G.K., A.R. Kubelik, K.J. Livak, J.A. Rafalski, and S.V. Tingey. 1990. DNA polymorphism amplified by arbitrary primers are useful as genetic markers. Nucleic Acids Res. 18:6531-6535.

Yue, G., Y. Li, F. Chen, S. Cho, L. Chuan Lim, and L. Orban. 2002. Comparison of three DNA marker systems for assessing genetic diversity in asian arowana (Scleropages formosus). Electrophoresis 23:1025-1032.

Zietkiewicz, E., A. Rafalski, and D. Labuda. 1994. Genome fingerprinrting by simple sequence repeat (SSR)- Anchored polymerase chain reaction amplification. Genomics 20:176-183.

Zohary, M. 1952. A monographical study of the genus Pistacia. Palestine J. Bot. Jerusalem Ser. 5:187-228. 